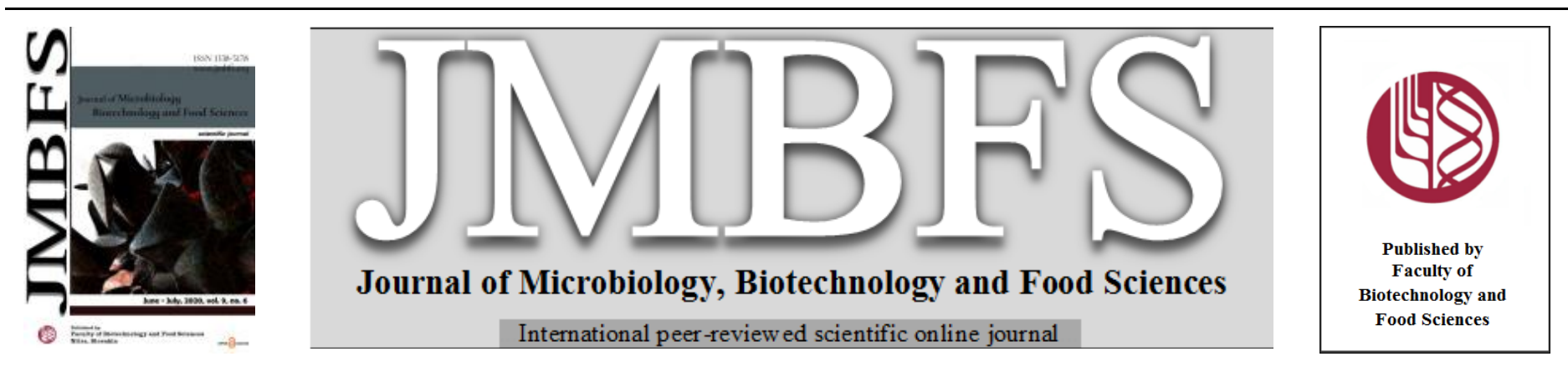

\title{
CHEMICAL COMPOSITION, ANTIMICROBIAL AND INSECTICIDAL ACTIVITIES OF CITRUS PARADISI PEEL ESSENTIAL OIL FROM ALGERIA
}

\author{
Ayache Kaouthar Nour el Houda ${ }^{1 *}$,Boudina Ali ${ }^{1}$,Abderrahmani Ahmed ${ }^{2}$, Oukil Salah ${ }^{3} \&$ Foudil-Cherif Yazid $^{1}$
}

Address(es):

${ }^{1}$ University of Sciences and Technology Houari Boumediene, Faculty of Chemistry, Laboratory of Functional Organic Analysis,BP32, El-Alia, Bab-Ezzouar, 16111 Algiers, Algeria Tel: +213 -551-07-63-91.

${ }^{2}$ University of Sciences and Technology Houari Boumediene, Faculty of Biology, Laboratory of Microbiology, BP32, El-Alia, Bab-Ezzouar, 16111 Algiers, Algeria Tel: +213 -551-07-63-91.

${ }^{3}$ National Institute of Agronomic Research of Algeria,Division of Plant Protection Mahdi Boualem,Baraki, El-Harrach, Algiers, Algeria.

*Corresponding author: ayachekaouthar@yahoo.com

doi: $10.15414 / j m b f s .2020 .9 .6 .1093-1098$

\section{ARTICLE INFO}

Received 16. 6. 2019

Revised 12. 1. 2020

Accepted 20.1.2020

Published 1. 6. 2020

Regular article OPEN $\partial_{\text {ACCESS }}$

\begin{abstract}
The essential oil obtained by microwave-assisted hydro-distillation (MAHD) and hydrodistillation (HD) techniques from the peel of grapefruit (Citrus paradisi. L) from Algeria was analyzed by gas chromatography-flame ionization detector (GC-FID) and gas chromatography / mass spectrometry (GC/MS). Twenty-one constituents were identified in essential oils obtained by HD and twentyeight constituents in essential oils by MAHD, representing respectively $99.11 \%$ and $99.74 \%$ of the total oil. The main constituents were limonene $(85.54 \%-87.51 \%)$ for MAHD and HD, $\beta$-myrcene $(2.99 \%-3.24 \%)$, nootkatone $(1.78 \%-1.80 \%)$. The antimicrobial activity of the essential oils was evaluated by disc diffusion method. The results showed interested inhibition growth against the tested bacteria (Escherichia coli, Pseudomonas aeruginos, and Staphylococcus aureus)and the yeast (Candida albicans), with an inhibition zone ranging from 4 to $20 \mathrm{~mm}$.Both essentials oils showed no effect against Aspergilusniger, Verticillium $s p$ and Thielaviopsis sp. The insecticidal activity was investigated against adults ceratitis capitata. Both essential oils showed a toxic effect against this insect $\left(\mathrm{LD}_{50}: 9.12 \mu 1 \mathrm{EO} / \mathrm{ml}\right.$ of acetone; $\mathrm{LD}_{90}: 13.18 \mu 1 \mathrm{EO} / \mathrm{ml}$ of acetone).
\end{abstract}

Keywords: Citrus paradisi, essential oil, hydrodistillation, microwave-assisted hydro-distillation, antimicrobial activity, insecticidal activity, Ciratitis Capitata

\section{INTRODUCTION}

Citrus paradisi (Rutaceae) has greater value in human diet (Malik, 1994), popularly called grapefruit, its tree grows up to 3-5 $\mathrm{m}$ hig and its fruit is mostly big and globular in bright yellow or lemon colored. The grapefruit is believed to have arisen from the pomelo or shaddock (Citrus grandis) or as a hybrid between pomelo and sweet orange (Bender and Bender, 2009; Adenge, 2007). Citrus paradisi is a rich source of bioactive molecules including flavonoids, sugars, organic acids, phenolic compounds, steroids and triterpenoids (Kelebek, 2010; Zhang et al., 2011). The peel oil has a strong and desirable aroma widely used in industrial flavoring of foods, beverages, pharmaceutical products, perfumes and cosmetics, as is common with other citrus oil (Pisano, 1986).

Many researches have been carried out on the chemical composition of grapefruits essential oils obtained by hydrodistilation (Caccioni et $\boldsymbol{a l}$., 1998; Ferhat et al., 2016), microwave (Uysal et al., 2011; Ferhat et al., 2016), cold press (Ferhat et al., 2016; Kirbaslar et al., 2009) or micro-wave hydrodiffusion (Jorge and Sánchez, 2000) belonging to different region in the world. These studies revealed the limonene as major compound in both oils. Whereas other components such $\alpha$-pinene, $\beta$-pinene, sabinene, myrcene, $\gamma$-terpinene, nootkatoone, octanal, nonanal, decanal, geraniol and geranial were present on remarkable amounts. It is interesting to note that the essential oils investigated have various compositions due to the origin, development stage of the collected plant material, seasonal, environmental and experimental conditions.

Grapefruits extract and their compounds are known to exhibit various biological activities including antioxidant (Bousbia et al., 2009; Ghasemi et al., 2009; Jun Yu et al., 2005), antibacterial (Karioti et al., 2012; Jun Yu et al., 2005; Benavente-Garcia et al., 1997), anticancer (Kotamballi et al., 2012), antiinflammatory, antiallergenic, analgesic (Viuda-Martos et al., 2007; Tsujiyama et al., 2013), antifungal (Karioti et al., 2012; Viuda-Martos et al., 2008) and insecticidal (Giatropoulos $\boldsymbol{e} t \boldsymbol{a l}$., 2012). In addition the citrus peel extract demonstrate the inhibitory effect of the Adipogenesis caused from high fatinduced dio model (Karagozlu et al., 2016).
However we have not found any information on the biological effects of essential oil from Citrus paradisi peels of Algerian origin. The aim of this study was the investigation of the chemical composition of this essential oil obtained by hydrodistillation assisted by microwave heating and hydrodistillation, respectively. Therefore, the comparison of the two techniques in terms of yields and composition were reported. The antimicrobial activity of the essential oils was tested against three bacteria (Escherichia coli, Pseudomonas aeruginosand Staphylococcus aureus), the yeast Candida albicans and three fungi (Verticillium sp., Verticilliumspand Thielaviopsis). The insecticidal activity of the peel of Citrus paradisiessential oil obtained by hydrodistillation was investigated against adults ceratitis capitata.To the best of our knowledge, this investigation can be considered as the first information on the study of insecticidal activity of grapefruit peel essential oil from Algeria.

\section{MATERIAL AND METHODS}

\section{Plant material}

In this study, $5 \mathrm{Kg}$ of fruits of Citrus paradisi were collected on February 2015 from the horticultural station located at Mitidja area, $50 \mathrm{~km}$ west of Algier (Bougara, Algeria) (36 $31^{\prime} 59.99^{\prime \prime} \mathrm{N}$ and $\left.3^{\circ} 04^{\prime} 60.00^{\prime \prime} \mathrm{E}\right)$. After collection, the peel was separated from the freshly picked fruits and chopped into $1 \mathrm{~cm}$ pieces, before used for extraction.

\section{Essential oil}

\section{MAHD process}

The peel of the fresh grapefruit was removed and $100 \mathrm{~g}$ was weighed and added into $1 \mathrm{~L}$ round bottom flask containing $50 \mathrm{~mL}$ of water. The oil extraction was carried out at atmospheric pressure for $30 \mathrm{~min}$. The flask was connected to a Clevenger-type apparatus located outside the microwave oven. In this process, we had to add some distilled water in the extraction flask. The Essential oil was 
removed from the aqueous medium by a simple decantation. After separation, the essential oil was dried over anhydrous sodium sulphate and stored at $4{ }^{\circ} \mathrm{C}$ until used for analysis. MAHD was performed three times and the mean value was reported.

\section{HD process}

The peel of the fresh grapefruit was removed and $100 \mathrm{~g}$ was weighed and subjected to hydrodistillation for $3 \mathrm{~h}$ using a Clevenger-type apparatus; with 500 $\mathrm{ml}$ of water. The essential oil was removed from the aqueous medium by a simple decantation. After separation, the essential oil was dried over anhydrous sodium sulphate and stored at $4^{\circ} \mathrm{C}$ until used for analysis. HD was performed three times and the mean value was reported.

\section{Gas chromatography and gas chromatography coupled to mass spectrometry analyses}

GC-FID system (Agilent, CA, USA, 2000) was used for GC analysis fitted with a fused-silica capillary column containing a non-polar stationary phase HP-5ms $(30 \mathrm{~m} \times 0.25 \mathrm{~mm} \times 0.25 \mu \mathrm{m}$ film thickness). The column temperature program was $60^{\circ} \mathrm{C}$ for $8 \mathrm{~min}$, then was increased at $2^{\circ} \mathrm{C} / \mathrm{min}$ to $250^{\circ} \mathrm{C}$ and held at $250{ }^{\circ} \mathrm{C}$ for $15 \mathrm{~min}$. A $0.2 \mu \mathrm{L}$ of the essential oil was injected into the splitless GC inlet Injector and detector temperature were kept at $250^{\circ} \mathrm{C}$. The carrier gas was nitrogen flowing through the column at $0.3 \mu \mathrm{L} / \mathrm{min}$.

GC-MS (Agilent Technologies) system comprising a 6890 gas chromatograph equipped with HP-5MS capillary column $(30 \mathrm{~m} \times 0.25 \mathrm{~mm} \times 0.25 \mu \mathrm{m}$ film thickness), coupled to a quadrupole HP mass spectrometer (Agilent Technologies) MSD 5973, was operated using the following conditions: carrier gas, He; flow rate, $0.3 \mathrm{~mL} / \mathrm{min}$, splitless mode; injected volume, $0.2 \mu \mathrm{L}$ of essential oil; injection temperature, $250{ }^{\circ} \mathrm{C}$. The used ionization mode was electronic impact at $70 \mathrm{eV}$. The ion source and interface temperature were 230 and $250{ }^{\circ} \mathrm{C}$, respectively, mass range was $30-600 \mathrm{~m} / \mathrm{z}$. Oven temperature program was the same given above for GC. The homologous n-alkane series $C_{5}$ $C_{28}$ injected in GC-MS under the same conditions as the essential oils were used to calculate the retention indices.

The constituents of the oil were identified by using standard reference compounds and also by matching the mass spectra fragmentation pattern with National Institute of Standards and Technology (NIST) Mass Spectra Library stored in the GC-MS database.

The retention indices of the volatile extract constituents compared with those of the published index data (ADAMS, 2007) are used to confirm the identification.

\section{Antimicrobial activity}

The antimicrobial activity of the essential oils was evaluated by disc diffusion method as described by Bauer (Bauer et al., 1969) using Mueller-Hinton agar for bacteria and SAB (Sabouraud) agar for fungi and yeast with determination of inhibition zones.

\section{Microbial strains}

The antimicrobial activity of the essential oils was tested against a panel of microorganisms and fungi including Escherichia coli ATCC 25922 and Pseudomonas aeruginosa ATCC 27853, the Gram-positive bacterium Staphylococcus aureus ATCC 25923 (SARM), three filamentous fungi, AspergillusnigerATCC 16404, Verticilliumdahliae,Thielaviopsisspp., and the yeast Candida albicans ATCC 10231.

\section{Disc diffusion method}

Bacterial and yeast suspensions were prepared from colonies resuspended in 10 $\mathrm{mL}$ of $\mathrm{NaCl}(0.9 \%)$, and homogenized to obtain an inoculum with an opacity of $0.5 \mathrm{~F}\left(-10^{8}\right.$ cells/ $\left.\mathrm{mL}\right)$. After spreading these suspensions by sterile swabs on Mueller Hinton agar and Sabouraud agar respectively, sterile standard empty antibiotic discs (6 $\mathrm{mm}$ in diameter) were impregnated with various volumes $(10$, 30 and $50 \mu \mathrm{L}$ ) of each essential oil and then deposited on the surface of Petri dishes. The incubation was carried out at $37^{\circ} \mathrm{C}$ overnight. The antibacterial and anti-yeast activities were estimated by measuring the diameter of growth inhibition around the disks, DMSO and Erythromycin were used as negative and positive control; each assay was performed three times.

To evaluate the antifungal activity, $2 \mu \mathrm{L}$ containing approximately $10^{4}$ spores $\mathrm{x}$ $\mathrm{mL}^{-1}$ were spotted onto Sabouraud agar at $1.5 \mathrm{~cm}$ distance from the impregnated discs. The dishes were incubated at $28{ }^{\circ} \mathrm{C}$ for 3 days. The antifungal activities were monitored by the ratio of the fungal growth diameter in absence and presence of the essential oil. Each assay was performed three times.

\section{Insecticidal activity}

\section{Insect culture}

The Mediterranean fruit fly (medfly), Ceratitis capitata (Wiedemann) (Diptera: Tephritidae) is one of the mostnotorious insect pests of citrus species causing extensive fruit losses worldwide (Mavrikakis et al., 2000). This insect is a highly polyphagous species, having more than 300 host fruits (Liquido et al. 1990).

Strain of Ceratitis capitata (C. capitata) used in this study was obtained from the laboratory of I.N.R.A.A (National Institute of Agronomic Research of Algeria).

Adults of $C$. capitata were kept in parallelepiped cage $(40 \times 50 \times 40 \mathrm{~cm})$, covered by a fine mesh cloth for ventilation, with easy access to liquid solution containing a mixture of water, sugar, citric and benzoic acid on a cotton wick.

The culture was placed at $26 \pm 2{ }^{\circ} \mathrm{C}, 40 \pm 5 \%$ relative humidity and photoperiod of 12:12-h (Light/Dark)

All experiments were carried out under the same environmental conditions.

\section{Insecticidal bioassays}

Ten adult insects were put into plastic bottles, covered by a fine mesh cloth for ventilation. A cotton wick treated with a mixture of alimentation (sugar solution) and $5,6,8,9,10,12 \mu \mathrm{L}$ of essential oil in $1 \mathrm{~mL}$ of acetone was placed in Petri dishes and put into each plastic bottle and covered immediately. Mortality was determined after $72 \mathrm{~h}$. Acetone was used as negative control. Each concentration was replicated four times with ten individuals per each replicate in a completely randomized design without subsamples.

Recorded numbers of dead insects among a population treated with biopesticide cloud is not especially the actual number of individuals killed by this biopesticide cloud. For this, we have used Abbott's formula (Abbott, 1925) for correcting the mortality rates.

The mortality rates are converted into probits (Ghosh, 1984). These probits are plotted against neperian logarithm to assess the lethal dose $\left(\mathrm{LD}_{50}\right)$ using the Millerand Tainer method (Miller and Tainter, 1944); $\mathrm{DL}_{50}$ and $\mathrm{DL}_{90}$ were calculated from the plot of regression lines.

\section{Statistical analysis}

All experimental results, represented as mean \pm standard error (SE), were subjected to statistical analysis performed by using one-way analysis of variance (ANOVA in XLSTAT software on Microsoft Excel 2007), differences at $p<0.05$ were considered statistically significant.

\section{RESULTS AND DISCUSSION}

The analytical results and the yields obtained for the different samples are illustrated in Table 1. All essential oils have a characteristic odor. The oil extracted by HD has a pale yellow color when the oil obtained by MAHD is colorless.

The percentages yields (based on dry weight (w/w) of essential oils obtained by HD and MAHD are $0.20 \% \pm 0.015$ and $0.30 \% \pm 0.015(\mathrm{w} / \mathrm{w})$ respectively.

The reports in the literature revealed a similar yield for the Pakistan grapefruits peel $(0.20 \%)$ (Kamal et al., 2011). But significant differences were reported for Nigerian (0.52-0.79\%) (Karioti et al., 2012; Okunowo et al., 2013), Turkish $(0.44 \%)$ (Uysal et al., 2011) and Algerian (0.11\%) (Ferhat et al., 2016) grapefruit peel obtained by HD. In addition, the percentage of essential oils obtained by MAHD is higher than that of the Algerian grapefruits peels (Ferhat et al., 2016) and lowers than that of the Turkish essential oil (Uysal et al., 2011).

Table 1 Chemical composition of volatile extracts from Citrus paradisi peels obtained by microwave-assisted hydro-distillation (MAHD) and hydro-distillation (HD).

\begin{tabular}{llllllll}
\hline $\mathbf{N o}$ & $\mathbf{C o m p o u n d s}^{\mathbf{a}}$ & $\mathbf{R T}^{\mathbf{b}}$ & Class $^{\mathbf{a}}$ & $\mathbf{R I}^{\mathbf{c}}$ & RI $^{\mathbf{d}}$ & $\mathbf{( \% )}^{\mathbf{e}} \mathbf{H D}$ & $\mathbf{( \% )}^{\mathbf{e}} \mathbf{M A H D}$ \\
\hline $\mathbf{1}$ & $\alpha$-Pinene & 8.73 & $\mathrm{MH}$ & 932 & 930 & $0.89 \pm 0.01$ & $0.86 \pm 0.05$ \\
$\mathbf{2}$ & $\beta$-Pinene & 11.03 & $\mathrm{MH}$ & 979 & 979 & $1.06 \pm 0.03$ \\
$\mathbf{3}$ & $\beta$-Myrcene & 12.20 & $\mathrm{MH}$ & 998 & 996 & $2.99 \pm 0.20$ & $3.24 \pm 0.20$ \\
$\mathbf{4}$ & $\delta$-3-Carene & 12.97 & $\mathrm{MH}$ & 1010 & 1009 & $0.77 \pm 0.12$ & $0.90 \pm 0.04$ \\
$\mathbf{5}$ & D-Limonene & 15.65 & $\mathrm{MH}$ & 1044 & 1040 & $87.51 \pm 1.06$ & $85.54 \pm 1.50$ \\
$\mathbf{6}$ & $\beta$-Ocimene E & 16.27 & $\mathrm{MH}$ & 1058 & 1051 & $0.56 \pm 0.02$ & $0.86 \pm 0.01$
\end{tabular}




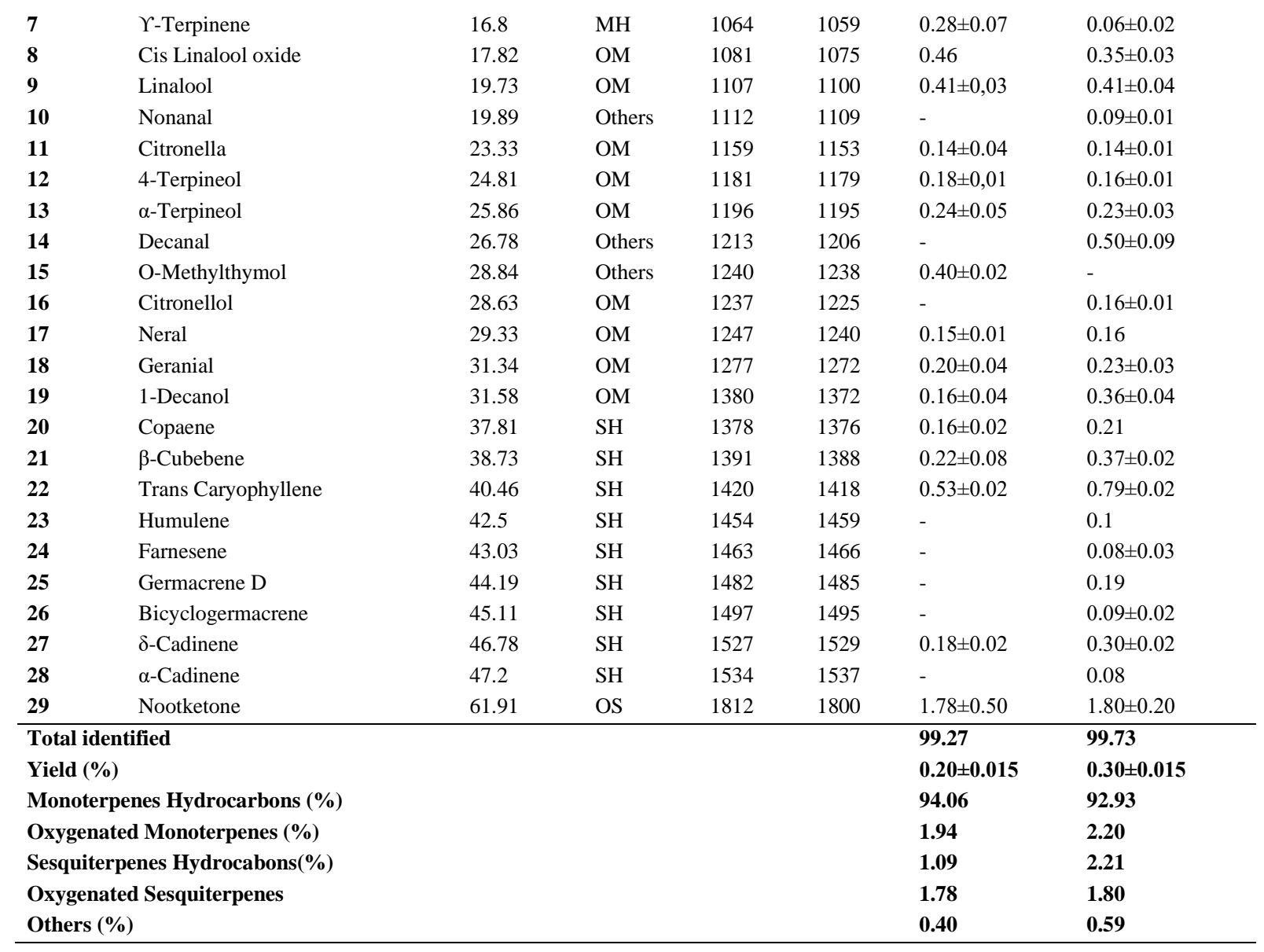

Note: ${ }^{\mathrm{a}}$ Compounds identified according their families on HP-5ms column. ${ }^{\mathrm{b}}$ Retention times. ${ }^{\mathrm{c}}$ Retention indices given in literature (NIST on non-polar HP5MSTM or DB5 capillary column). ${ }^{\mathrm{d}}$ Retention indices with respect to C5-C28 n-alkanes calculated on non-polar HP5MSTM capillary column. ${ }^{\mathrm{e}} \mathrm{Percentage}$ calculated by GC-FID on non polar HP5MSTM capillary column. Traces $(<0.05 \%)$, Mean \pm SD $(n=3)$

The volatile compounds identified in both essential oils are listed in Table 1 according to their elution order on non-polar column as the means of three replicates. Twenty one constituents were identified in essential oils obtained by HD (Fig.1) and twenty eight compounds in essential oils obtained MAHD (Fig.2), representing respectively $99.11 \%$ and $99.74 \%$ of the total oil.

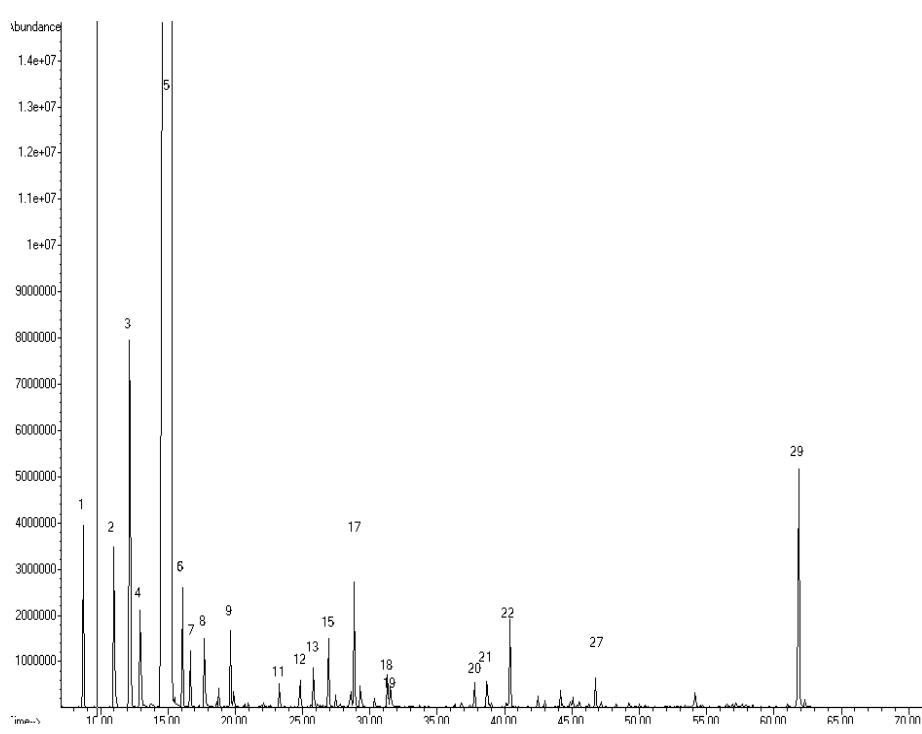

Figure 1 Chromatogram of essential oil of Citrus paradisi peels obtained by hydro-distillation (HD).

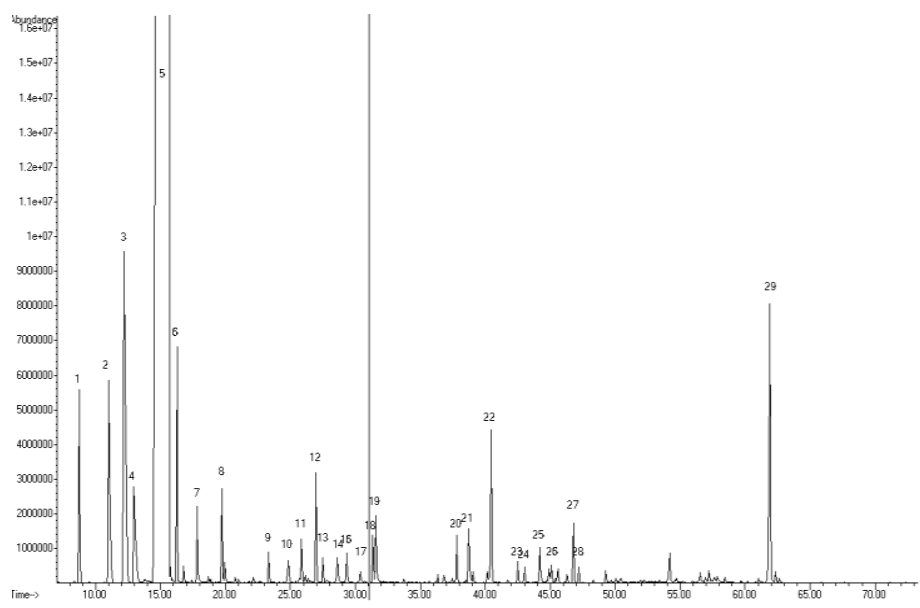

Figure 2 Chromatogram of essential oil of Citrus paradisi peels obtained by microwave-assisted hydro-distillation (MAHD).

The monoterpenes hydrocarbons constituted the most dominant chemical group (94.06\% in HD vs $92.08 \%$ for MAHD), while the oxygenated monoterpenes $(1.7$ $\%$ in HD vs $1.66 \%$ for MAHD), sesquiterpenes (1.71\% in HD vs $2.21 \%$ for MAHD) and oxygenated sesquiterpens $(1.78 \%$ in HD vs $1.8 \%$ for MAHD) showed lower contents.

Limonene was the major compound in HD essential oil $(87.51 \%)$, followed by $\beta$ myrcene $(2.99 \%)$, nootkatone $(1.78 \%), \beta$-pinene $(1.06 \%), \alpha$-pinene $(0.89 \%), \delta$-3 carene $(0.77 \%)$, (E) $\beta$-ocimene $(0.56 \%)$, trans-caryophyllene $(0,53 \%)$. The other important constituents, less than $(0.50 \%)$ were detected such as linalool $(0.41 \%)$, cis-linalool oxide $(0.46 \%)$, neral $(0.4 \%), \alpha$-terpineol $(0.24 \%)$ and $\beta$-cubebene $(0.22 \%)$.

The results for essential oil extracted by MAHD were in agreement with those obtained of HD essential oils. Indeed, the major compound was limonene $(85.54 \%)$ followed by $\beta$-Mycene $(3.24 \%)$, nootketone $(1.80 \%), \quad \beta$-pinene $(1.47 \%), \delta$ - 3-carene $(0.90 \%), \alpha$-pinene $(0.86 \%), \beta$-ocimene $\mathrm{E}(0.86 \%)$ and transcaryophyllene $(0.79 \%)$. Other compounds were detected in appreciable amounts, 
such as decanal $(0.50 \%)$, linalool $(0.41 \%), \beta$-cubebene $(0.37 \%)$, trans-geranial $(0.36 \%)$, cis-linalool oxide $(0.35 \%)$, cis-geranial $(0.23 \%), \alpha$-terpineol $(0.23 \%)$, copaene $(0.21 \%)$, 4-Terpineol $(0.16 \%)$ and citronella $(0.14 \%)$.

The various studies on essential oils of grapefruit peel extracted by hydrodistillation showed a wide variety of chemical composition. The major compounds of essential oils of citrus paradisi originating from Soudan (E Kamali et al., 2015)were limonene $(74.45 \%)$, sabinene $(1.21 \%), \alpha$-pinene (3.74\%), decanal (1.18\%), caryophylene $(1.15 \%)$ and $\alpha$-farnesene $(1.13 \%)$ However, the chemical composition of Italian essential oils (Caccioni et al. 1998) was dominated by limonene $(93.70 \%)$ and myrcene $(1.86 \%)$. The essential oil of Nigeria showed two chemotypes: the first one (Kariotietal., 2012)was characterized by limonene $(81.86 \%), \alpha$-pinene $(2.11 \%)$, caryophylene $(1.88 \%)$, myrcene $(7.25 \%)$, octanal $(1.68 \%)$ and $\beta$-phellandrene $(1.18 \%)$, whereas the second one (Okunowo et al., 2013)was marked by the dominance of limonene $(94.2 \%)$ and $\alpha$-pinene $(0.7 \%)$. The mains constituents detected in Turkey (Uysal et $a l ., 2011)$ peels essential oils were limonene $(88.6 \%), \beta$-pinene $(1.2 \%), \alpha$ terpinene $(1.0 \%), \alpha$-pinene $(0.7 \%)$, myrcene $(0.9 \%)$, linalool $(0.7 \%)$. This composition is relatively comparable to that of our study, indeed the mains componentswere limonene $(87.51 \%), \alpha$-pinene $(0.89 \%)$, myrcene $(2.99 \%)$ linalool $(0.41 \%)$ and nootkatone $(1,78 \%)$. It is interesting to note that nootkatone compound has not been detected in any essential oil previously mentioned in this text. According to investigation of the essential oil of Algerian origin (Ferhat $\boldsymbol{e}$ al., 2016), the essential oil of Citrus paradisi (variety bouquet of nice) studied was rich in limonene $(93.01 \%)$, myrcene $(1.84 \%)$ and linalool $(1.40 \%)$. It should be noted that the investigation of the essential oils of Pakistan origin (El Kamali et al., 2015) revealed the presence of nootkatone in appreciable amounts $(4.37 \%$ $10.9 \%$ ) according to the mode of drying pretreatment of peels.
In the case of chemical composition of essential oils extracted by microwave, there are only few studies on citrus paradisi. The investigation on essential oils of Turkey (Uysal et al., 2011) revealed the limonene (91.5\%) and linalool (1.1\%) as mains components. These two compounds were also detected in the Algerian oil (Ferhat et al., 2016) with similarly percentages, however two other compounds were identified, namely linalyl acetate (1.10\%) and myrcene $(1.73 \%)$. This composition is very different from our one. Indeed limonene $(87.51 \%)$ and myrcene $(2.99 \%)$ are the common compounds but we have also detected $\beta$-pinene $(1.06 \%)$ and nootkatone $(1.78 \%)$ with appreciable amount.

\section{Antimicrobial activity}

The antimicrobial properties of essential oils are due to the presence of active constituents, and can be attributed to the monoterpenes, sesquiterpenes and related alcohols, other hydrocarbons and phenols (Griffin et al., 1999).

Thus, we have undertaken a study on antimicrobial activity of essential oils from Citrus paradisi obtained by HD and MAHD. The antimicrobial activity was evaluated by the disc diffusion method against three bacterial strains and four molds (Table 2).

The results showed that the grapefruit peel essential oils inhibits the growth of all tested bacteria except for P.aeruginosa, which is inhibited only by the essential oil extracted by the conventional method HD. However, these oils inhibited only the growth of Candida albicans andthis inhibition depends on both the oil volume used and the nature of strain

\begin{tabular}{|c|c|c|c|c|c|c|c|}
\hline \multirow{2}{*}{$\begin{array}{l}\text { Essential oils } \\
\text { Volume }(\mu \mathrm{L})\end{array}$} & \multicolumn{3}{|c|}{ MAHD } & \multicolumn{3}{|c|}{ HD } & \multirow{2}{*}{$\begin{array}{c}\text { Erythromycin } \\
(30 \mu \mathrm{L} / \mathrm{disc})\end{array}$} \\
\hline & 10 & 30 & 50 & 10 & 30 & 50 & \\
\hline E. coli & $4 \pm 0.50$ & $12 \pm 1$ & $13 \pm 1.22$ & - & 12 & $15 \pm 1$ & $33 \pm 1.03$ \\
\hline P. aeruginosa & - & - & - & - & $12 \pm 0.50$ & $15 \pm 1$ & $39 \pm 0.50$ \\
\hline S.aureus(methicillin resistant) & 9 & 11 & $13 \pm 1$ & $10 \pm 1$ & 13 & 15 & $36 \pm 0.75$ \\
\hline C. albicans & $8 \pm 0.60$ & $11 \pm 1$ & 12 & - & $17 \pm 0.90$ & $20 \pm 1.30$ & - \\
\hline V. dahliaeKleb & - & - & - & - & - & - & - \\
\hline A. niger & - & - & - & - & - & - & - \\
\hline Thielaviopsisspp. & - & - & - & - & - & - & - \\
\hline
\end{tabular}

Both essential oils showed the same activity against all bacterial strains with moderate inhibition zones. As for $C$. albicans, the most important inhibition diameter was observed with the oil obtained by HD method (20 mm vs $12 \mathrm{~mm}$ ). Furthermore, the essential oils exhibited moderate antibacterial activity compared with the control antibiotic, except for $C$. albicans who was not inhibited by Erythromycin.

Several studies have shown the no activity of different essential oils against $P$. aeruginosa (Cosentino et al., 1999; Tepe et al., 2005; Matasyoh et al., 2007).I is important to note that the essential oil of Citrus paradise from Turkey showed no effect against this bacterium (Uysaletal., 2011), which was certainly due to the difference between the chemical compositions of the two oils.

According to the literature, limonene is mainly responsible for antimicrobia activity of the Citrus genus oils. So, the antimicrobial activity of the essential oils of grapefruit peel can be attributed to limonene, the main constituent in the two oils (Uysal et al., 2011; Stashenko et al., 1996; Merle et al., 2004; Sharma et al., 2004).

Essential oil obtained by HD method was more effective than that obtained by MAHD and this result can be explained by the higher percentage of limonene obtained by HD. Thus, we may conclude that the activity of the essential oil extracted by $\mathrm{HD}$ against $P$. aeruginosa is attributed to the synergistic effect between the different components of this oil.

To the best of our knowledge, the results presented here can be considered as the first information on the comparison of antimicrobial activity of the grapefruit peel essential oils from Algeria obtained by MAHD and HD methods.

\section{Insecticidal activity}

The major components of plant essential oils, having a low risk for environmen and humans, can be used as natural alternatives for conventional insecticide (Isman, 2000).

Thus, we have undertaken a study on insecticidal activity of essential oil of Citrus paradise peel obtained by hydrodistillation.

In the literature, a toxicity of some essential oil against $C$. capitata (larvae and adults) was examined and showed activity against this specie.(Giatropoulos $\boldsymbol{e t}$ al., 2012; Benelli et al., 2012).

The result showed that the grapefruit peel essential oil has a toxic effect against adults of $C$. capitata with more than $60 \%$ of mortality at higher concentrations $(10,12 \mu \mathrm{l} / \mathrm{ml})$. Also at lower concentrations $(5,6 \mu \mathrm{l} / \mathrm{ml})$, the toxicity of the essential oil was not significant (Fig.3), with $\mathrm{LD}_{50}$ and $\mathrm{LD}_{90}$ values of $9.12 \pm 2.5$ $\mu \mathrm{EO} / \mathrm{ml}$ of acetone and $13.18 \pm 2 \mu \mathrm{EO} / \mathrm{ml}$ of acetone respectively, $(90 \%$ of mortality after $72 \mathrm{~h}$ ). Previous studies on the toxicity of three Citrus genus from Greece showed that these essential oils have a toxic effect on larvae of $C$.capitata, doses lower than $0.8 \mu \mathrm{l} / \mathrm{g}$ of food were not active against larvae, while doses higher than $13 \mu \mathrm{l} / \mathrm{g}$ of food killed the higher proportion of larvae (Benelli $\boldsymbol{e t}$ al., 2012).

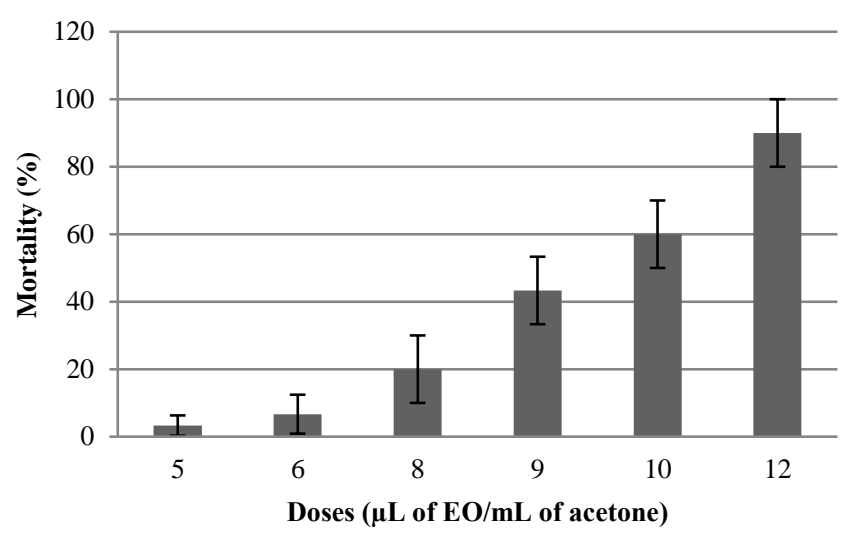

Figure 3 Mortality of adults of $C$. capitita after $72 \mathrm{~h}$ of treatment with different concentrations of Citrus paradisi essential oil, Means $(n=5)$ using 10 adults per replicate.

In the present research, the insecticidal activity of the essential oil of grapefruit peel can be attributed to limonene, the main constituent of the grapefruit peel essential oil, due to its pronounced toxic effect, as already discussed (Giatropoulos et al., 2012; Papachristos et al., 2009; Chantraine et al., 1998; Kassir et al., 1989; Michaelakis et al., 2008). Previous research showed that the hydrocarbons limonene, $\Upsilon$-terpinene and myrcene are mainly responsible for the toxicity of Citrus genus oil against $C$. capitata with LC50, calculated respectively $(6.2,7,9.6 \mu \mathrm{l} / \mathrm{g})$, whereas the pinenes are the least active components (Benelli $\boldsymbol{e t}$ al., 2012). Therefore, the dominate family of detected volatile were monoterpenes hydrocarbons $(94.06 \%)$, while the oxygenated monoterpenes $(1.7 \%)$, sesquiterpenes $(1.71 \%)$ and oxygenated sesquiterpenes $(1.78 \%)$ contents 
were very low. So, we can conclude that the active components of monoterpenes hydrocarbons can be responsible for the toxicity of grapefruit peel essential oil against the adults $C$. capitata.

\section{CONCLUSION}

The composition of the grapefruit peel essential oils obtained by both methods was found to be similar. Both essential oils showed the same antimicrobia activity against all bacterial strains and moulds except for Pseudomonas aeruginosa, which was inhibited only by the oil extracted by the conventional method HD. Essential oil of Citrus paradisi peel obtained by HD showed an interesting insecticidal activity against $C$.capitata.

Finally, our studies showed important data about the chemical composition, antimicrobial and insecticidal activities of the grapefruit peels essential oil from Algeria, which could be a potential natural flavor additive substituting for chemicals in food preservation and can become an interesting alternative for the conventional insecticide for plant protection.

\section{REFERENCES}

ABBOTT,W., 1925.A method of computing the effectiveness of an insecticide.Journal of Economic Entomology, 18:265267.https://doi.org/10.1093/jee/18.2.265a

ADAMS, R., 2007. Identification of Essential Oil Components by Gas Chromatography/Mass Spectrometry,Allured Publishing Corporation, Caro Stream, IL.

ADENGE,A., 2007. Haematopoetic effect of methanol need extract of citrus paradisimacfad (grapfruit) in wistar rats. Biomedical Research,19:23 -26 http://www.alliedacademies.org

BAUER, A., KIRBY, W., SHERRIS, J., TURCK, M. 1966. Antibiotic susceptibility testing by a standardized single disk method, Americain Journal of clinical pathology, 45, 493.https://doi.org/10.1093/ajcp/45.4 ts.493

BENAVENTE-GARCIA, O., CASTILLO, J., MARTIN, F., ORTUNO, A., DEL RIO J. 1997.Uses and properties of Citrus flavonoids.Journal of Agricultural and Food Chemistry, 45:4505-4515.http://www.mdpi.org

BENDER, D., BENDER, A. 2009.A dictionary of food and Nutrition. New York, USA:Oxford University press. DOI:10.1093/acref/9780199234875.001.0001 BENELli, G., FlAMINI, G., CANALE, A., CIONI PL., CONTI, B. 2012. Toxicity of some essential oil formulations against the mediterranean fruit fly Ceratitis capitata (Wiedemann) (DipteraTephritidae). Crop Protection, 42:223-229. https://doi.org/10.1016/j.cropro.2012.05.024

BOUSBIA, N., VIAN, A., FERHAT, M., MEKLATI, Y., CHEMAT, F. 2009. A new process for extraction of essential oil from Citrus peels: Microwave hydrodiffusion and gravity. Journal of Food Engineering, 90:409413.https://doi:10.1016/j.jfoodeng.2008.06.034

CACCIONI, R., GUIZZARDI, M., BIONDI, M., RENDA, A., RUBERTO, G. 1998. Relationship between volatile components of citrus fruit essential oils and antimicrobial action on Peniciliumdigitatum and Peniciliumialicum. Journal of Food Microbiology, 43:73-79. https://doi.org/10.1016/S0168-1605(98)00099-3 CHANTRAINE, J., LAURENT, D., BALLIVIAN, C., SAAVEDRA, G., IBANEZ, R., VILASECA, L.1998. Insecticidal activity of essential oils on Ae.Aegypti, larvae.Phytotherapy Research, 12:350-354 https://doi.org/10.1002/(SICI)1099-1573(199808)12:5<350::AID-

PTR311>3.0.CO;2-7

COSENTINO, S., TUBEROSO,CIG., PISANO, B.1999. In vitro antimicrobial activity and chemical composition of Sardinian Thymus essential oils.Letters in Applied Microbiology, 29: 130-135.

EL KAMALI, H., BURHAM, B., EL-EGAMI, A. 2015.Essential oil composition of internal fruit of Citrus paradisi from Sudan.american research thoughts journal,1(9): 2079-2085. http://dx.doi.org/10.6084/m9.figshare.1480470.

FERHAT, M., BOUKHATEM, M., HAZZIT, M., MEKLATI, B., CHEMAT F. 2016. Cold pressing, Hydrodistillation and microwave dry distillation of Citrus essential oil from Algeria: A comparative study. Electronic Journal of Biotechnology,S1:30-41.

GHASEMI, K., GHASEMI, Y., EBRAHIMZADEH, M. 2009. Antioxidant activity, phenol and flavonoid contents of 13 citrus species peels and tissues.Pakistan Journal of Pharmaceutical Sciences, 22: 2767-281.

GHOSH, MN. 1984. Satistical Analysis, Fundamentals of Experimental Pharmacology, $2^{\text {nd }}$ ed. Scientific Book Agency. Calcutta, pp 187-189.

GIATROPOULOS, A., PAPACHRISTOS, D., KIMBARIS, A., KOLIOPOULOS, G., POLISSIOU, G., EMMANOUEL, N., MICHAELAKIS, A. 2012. Evaluation of bioefficacy of three Citrus essential oils against the dengue vector Aedesalbopictus (Diptera: Culicidae) in correlation to their components enantiomeric distribution. Journal of Parasitology Research,111: 2253-2263.

https://doi.org/10.1007/s00436-012-3074-8.

GRIFFIN, S., WYLLIE, S., MARKHAM, J., LEACH, DN. 1999.Flavour and Fragrance Journal, 14: 322.

ISMAN MB.2000. Plant essential oils for pest and disease management. Crop Protection, 19: 603-608.https://doi.org/10.1016/S0261-2194(00)00079-X
JORGE, AP., SÁNCHEZ, M. 2000. Chemical Composition of Grapefruit Oil Concentrates. Journal of Essential Oil Research, 12(2): 167 169.https://doi.org/10.1080/10412905.2000.9699489

JUN,Y., LIMIN W., ROSEMARY, WALZMAN L., EDWARD, MILLER G., LEONARD, PIKE M., BHIMANAGOUDA, PATIL S. 2005. Antioxidant Activity of Citrus Limonoids, Flavonoids, and Coumarins.Journal of agricultural and food chemistry. 53: 2009-2014. https://pubs.acs.org/doi/10.1021/if0484632

KAMAL, GM., ANWAR, F., HUSSAIN,AI., SARRI, N., ASHRAF, MY. 2011. Yield and chemical composition of Citrus essential oils as affected by drying pretreatment of peels. Food Research International, 18(4): 1275-1282.

KARAGOZLU, M., KIM, M., LEE,M .2016. Citrus Peel Ethanol Extract Inhibits the Adipogenesis Caused from High Fat-Induced DIO Model. International Journal of Food Sciences and Nutrition,7:8-19. DOI: $\underline{10.4236 / \text { fns.2016.71002 }}$

KARIOTI, A., SKALTA, H., ADEBAYO, AG.2012. Constituents of the distilled essential oils of 7 Citrus reticulata and C. paradisi from Nigeria. Journal of Essential Oil Research 19(6): 520-522. https://doi.org/10.1080/10412905.2007.9699320

KASSIR, JT., MOHSEN,ZH., MEHDI NS. 1989. Toxic effects of limonene against Cx. Quinquefasciatus Say larvae and its interference with oviposition. Anz. Schädlingskde.1PflanzenschutzUmweltschutz, 62:19-21.

KELEBEK, H. 2010. Sugars, organic acids, phenolic compositions and antioxidant activity of Grapefruit (Citrus paradisi) cultivars grown in Turkey. Ind. Corps Production, 32: 269-274. https://doi.org/10.1016/j.indcrop.2010.04.023

KHAN,MN., MAHMUD, S., BALOCH, IH., REHMAN, S., MUNAWAR, MA .2010. Characterisation of essential oil of local varieties of Citrus paradis peel.Journal of Chemical Society of Pakistan,32: 571-573.

KIRBASLAR, F., TAVMAN, A., DULGER, B., TURKER, G.2009. Antimicrobial activity of Turkish Citrus peel oils. Pakistan Journal of Botany,41(6): 3212-3212.

KOTAMBALLI, N., CHIDAMBARA, M., JAYAPRAKASHA, G., SHIVAPPA, M., BHIMANAGOUDA, SP.2012.Citrus Monoterpens: Potential source of phytochemicals for concerprevention. Journal of the American Chemical Society,31:546-557.DOI: 10.1021/bk-2012-1093.ch031

LIQUIDO, N., CUNNINGHAM, R., NAKAGAWA, S.1990. Host plants of Mediterranean fruit fly (Diptera: Tephritidae) on the Island of Hawaii (1949-1985 Survey).Journal of Economic Entomology, 83: 1863 - 1878.DOI: 10.1093/jee/83.5.1863

MALIK, MN.1994. General horticulture 427 pulished by national book of foundation Islamabad, 437- 438

MATASYOH, J., KIPLIME,J., KARUBIU, N., HAILSTORKS, T. 2007. Chemical composition and antimicrobial activity of essential oil of Tarchonanthus camphorates. Food Chemistry, 101: 1183-1187. https://doi.org/10.1016/j.foodchem.2006.03.021

MAVRIKAKIS, P., ECONOMOPOULOS, A., CAREY, J.2000. Continuous winter reproduction of the Mediterranean fruit fly (Diptera: Tephritidae) in Heraklion, Crete, Southern Greece. Environmental Entomology, 29:1180-1187. https://doi.org/10.1603/0046-225x-29.6.1180

MERLE, H., MORON, M., BLAZQUEZ, M., BOIRA, H. 2004. Taxonomical contribution of essential oils in mandarins cultivars. Biochemical Systematics and Ecology,32:491-497.https://doi.org/10.1016/j.bse.2003.09.010

MICHAELAKIS, A., KOLIOPOULOS, G., MILONAS, P., KONTODIMAS, D., POLISSIOU, M., KIMBARIS, AC., PAPACHRISTOS, D. 2008. Activity of nonoxygenated versus oxygenated monoterpenes against mosquitoes.An attempt to correlate toxicity with chemical structure. In: A 7th Joint meeting of AFERP, GA, PSE \& SIF. Natural products with pharmaceutical, nutraceutical, cosmetic and agochemical interest, Athens.

MILLER LC, TAINTER ML.1944. Estimation of ED50 and its error by means of logarithmic probit paper.Proceedings of the Society for Experimental Biology and Medicine, 57: 261-264. https://doi.org/10.3181/00379727-57-14776

NJOROGE, S., KOAZE, H., KARANJA, P., SAWAMURA, M.2005.Volatile Constituents of Redblush Grapefruit (Citrus paradisi) and Pummelo (Citrus grandis) Peel Essential Oils from Kenya.Journal of Agricultural and Food Chemistry, 53: 9790-9794

OKUNOWO, W., OYEDEJI, O., AFOLABI, L., MATANMI, E. 2013.Essential oil of Grape Fruit (Citrus paradisi) peels and its antimicrobial activities.American Journal of Plant Sciences, 4: 19.https://doi.org/10.4236/ajps.2013.47a2001

PAPACHRISTOS, D., KIMBARIS, A., PAPADOPOULOS, N., POLISSIOU, M. 2009. Toxicity of citrus essential oils against Ceratitis capitata (Diptera: Tephritidae) larvae. Annals of Applied Biology, 155: 381389. https://doi.org/10.1111/j.1744-7348.2009.00350.x

PISANO, R. 1986.The future of natural essential oil in the flavor and fragrance industry. Perfume flavor, 11: 35-41.

SAYARI, N., SILA, A., BALTI, R., ABID, E., HAJLAOUI, K., NASRI, M., BOUGATEF, A. 2015. Antioxidant and antibacterial properties of Citrus paradise barks extracts during turkey sausage formulation and storage. Biocatalysis and Agricultural Biotechnology, 15: 1878 8181.https://doi.org/10.1016/j.bcab.2015.10.004 
SHARMA, N., TRIPATHI, A. 2008. Effects of Citrus sinensis (L.)Osbeckepicarp essential oil 9 on growth and morphogenesis of Aspergillusniger (L.) Van Tieghem. Microbiological Research, 163: $337-$ 344.https://doi.org/10.1016/i.micres.2006.06.009

STASHENKO, E., MARTINEZ, R., PINZDN, M., RAMFREZ, J. 1996. Changes in chemical composition of catalytically hydrogenated orange oil (Citrus sinensis). Journal of Chromatography, 752: 217222.https://doi.org/10.1016/s0021-9673(96)00481-5

TEPE, B., SOKMEN, M., SOKMEN, A., DAFERERA, D., POLISSIOU, M

2005. Antimicrobial and antioxidant activities of the essential oil and various extracts of Cyclotrichiumoriganifolium (Labill.)Manden and Scheng.Journal of Food Engineering,69: 335-342.https://doi.org/10.1016/j.jfoodeng.2004.08.024

TSUJIYAMA, I., MUBASSARA, S., AOSHIMA, H., HOSSAINS. 2013. Antihistamine release and anti-inflammatory activities of aqueous extracts of citrus fruits peels. Oriental Pharmacy and Experimental Medicine, 13: 175180.https://doi.org/10.1007/s13596-012-0093-Z

UYSAL, B., SOZMEN, F., OKSAL, S., KOSE, E. 2011. Essential oi composition and antibacterial activity of the grapefruit (CITRUS PARADISI.L) peel essential oils obtained by solvent free microwave extraction: comparison with hydrodistillation. International Journal of Food Science \& Technology, 46: 1455-1461.https://doi.org/10.1111/j.1365-2621.2011.02640.x

VIUDA-MARTOS, M., RUIZ-NAVAJAS, Y., FERNANDEZ-LOPEZ, J., PEREZ-ALVAREZ, J. 2007. Antibacterial activity of lemon (Citrus lemon L.), mandarin (Citrus reticulata L.), grapefruit (Citrus paradisi L.) and orange (Citrus sinensis L.).Essential oils. J. food saf 28: 567 576.https://doi.org/10.1111/j.1745-4565.2008.00131.X

VIUDA-MARTOS, M., RUIZ-NAVAJAS, Y., FERNÁNDEZ-LÓPEZ, J., PÉREZ-ALVAREZ, J. 2008.Antifungal activity of lemon (Citrus lemon L.), mandarin (Citrus reticulata L.), grapefruit (Citrus paradisi L.) and orange (Citrus L.) Essential oils Food Control, 113.https://doi.org/10.1016/j.foodcont.2007.12.003

ZHANG, M., DUAN, C, ZANG, Y., HUANG, Z., LIU, G. 2011.The flavonoid composition of flavedo and juice from the pummelo cultivar (Citrus grandis(L.)Osbeck and the grapefruit cultivar (Citrus paradisi) from China.Food Chemistry, 1530-1536.https://doi.org/10.1016/j.foodchem.2011.05.136 